\title{
Real-world efficacy and safety of eribulin in advanced and pretreated HER2-negative breast cancer in a Spanish comprehensive cancer center
}

Milana Bergamino Sirvén ${ }^{1}$, Adela Fernández-Ortega ${ }^{1}$, Agostina Stradella', Idoia Morilla', Catalina Falo', Silvia Vázquez ${ }^{1}$, Roser Castany ${ }^{1}$, Rafael Villanueva ${ }^{1}$, Sabela Recalde ${ }^{1}$ Valentí Navarro Pérez², Miguel Gil-Gil ${ }^{1}$ and Sonia Pernas ${ }^{1 *}$ (1)

\begin{abstract}
Background: Eribulin improves survival in pre-treated HER2-negative advanced breast cancer (ABC). However, limited data exist on co-morbidities and central nervous system (CNS) efficacy. The purpose of this study was to review eribulin's efficacy and safety in everyday clinical practice with special focus on age, body mass index (BMI) and central nervous system (CNS) activity.

Methods: An observational study was conducted in a series of HER2-negative ABC patients treated from January'14-December'17 outside a clinical trial. Objective Response Rate (ORR), Progression Free Survival (PFS), Overall Survival (OS), and association of clinical and pathological variables with outcome were evaluated.

Results: Ninety-five women were treated with at least one cycle of eribulin. Median age was 57 (33-83), and 18\% were obese. Median number of prior chemotherapies for ABC was $3(2-5)$ and $76 \%$ of patients had visceral metastases, including 21\% with CNS involvement. Most tumors were estrogen receptor-positive (79\%). ORR and stable disease (SD) at 6 months were 26.2 and 37.5\%, respectively. Remarkably, relevant CNS efficacy was observed with eribulin: $20 \%$ of patients obtained partial response and 25\% SD. Treatment was generally well tolerated and manageable, with 29\% grade 3 and 10.9\% grade 4 toxicities. Median PFS and OS were 4.1 months (CI95\% 3.2-4.9) and 11.1 months (CI95\% 9.5-14.7), respectively. Triple-negative disease, > 2organs involved and being younger than 70 years old were independent prognosis factors for worse OS in multivariate analysis. Most patients (75\%) progressed in pre-existing metastases sites.
\end{abstract}

Conclusion: In everyday clinical practice, eribulin's efficacy seems similar to pivotal trials. CNS-efficacy was observed. TNBC, $>2$ organs involved and being younger than 70 years old were independent prognosis factors for worse OS. Remarkably, less incidence of grade 4-toxicity compared to previous studies was found.

Keywords: Eribulin, Breast cancer, Real-world data, Brain metastases, Obesity, Progression pattern, Elderly patients

\footnotetext{
* Correspondence: spernas@iconcologia.net

${ }^{1}$ Department of Medical Oncology-Breast Cancer Unit, Insitut Catala

d'Oncologia (ICO)-H.U.Bellvitge- IDIBELL, Avinguda Gran Via 199-203,

08908-L'Hospitalet de Llobregat, Barcelona, Spain

Full list of author information is available at the end of the article
}

(c) The Author(s). 2019 Open Access This article is distributed under the terms of the Creative Commons Attribution 4.0 International License (http://creativecommons.org/licenses/by/4.0/), which permits unrestricted use, distribution, and reproduction in any medium, provided you give appropriate credit to the original author(s) and the source, provide a link to the Creative Commons license, and indicate if changes were made. The Creative Commons Public Domain Dedication waiver (http://creativecommons.org/publicdomain/zero/1.0/) applies to the data made available in this article, unless otherwise stated. 


\section{Background}

Eribulin mesylate is a synthetic analogue of the marine halicondrin $\mathrm{B}$, a microtubule-targeting agent approved for the treatment of metastatic breast cancer. Some preclinical data showed that eribulin can reverse the epithelial-mesenchymal transition (EMT), reducing cancer cell migration and invasion [1, 2]. Additionally, eribulin has an antiangiogenic effect and it can cause tumor vascular remodeling, leading to an increased perfusion into the tumor and metastases [3-5].

Two phase III randomised studies (EMBRACE and 301 trials) and a pooled analysis of these two studies showed that eribulin improved overall survival (OS) in patients with pretreated advanced breast cancer (ABC) [6-8]. The benefits of eribulin were achieved with a manageable toxicity profile in both studies. The beneficial effects of eribulin compared with the control were mainly observed in patients with triple-negative breast cancer (TNBC) or HER2-negative disease, in patients with $>2$ organs involved and in patients with visceral disease [8]. Moreover, a reduced incidence of new location metastases when patients are treated with eribulin has been reported in some retrospective studies, probably due to its biological effect [9-11]. In contrast, few data exist about prognostic and predictive factors of response with eribulin in everyday clinical practice $[12,13]$ . Efficacy in elderly patients, obese patients, or in patients with central nervous system (CNS) disease has not been well reported either [14-16].

Eribulin was approved in Spain in December 2013 for patients with HER2-negative recurrent or metastasic breast cancer previously treated with taxanes, anthracyclines and capecitabine unless patients were not suitable for those treatments [17-19]. The purpose of our study was to review eribulin's activity, in terms of progression-free survival (PFS) and OS, and tolerability in patients with HER2negative $\mathrm{ABC}$ treated at ICO-Hospitalet (Barcelona, Spain) outside of a clinical trial since its approval.

\section{Methods}

\section{Study population}

An observational study was conducted at ICO-Hospitalet to review patients with HER2-negative $\mathrm{ABC}$ consecutively treated with single-agent eribulin from January 2014 to December 2017 in an off-trial setting. All patients included may have received at least one cycle of eribulin $1.23 \mathrm{mg} / \mathrm{m} 2$ day 1 and 8 every 21 days. The treatment was continued until disease progression, unacceptable toxicity, or patient withdrawal. Age at diagnosis, body mass index (BMI), relevant comorbidities, Eastern Cooperative Oncology Group (ECOG) Performance Status, tumor subtype, visceral involvement, pre and post-eribulin chemotherapy regimens, response rate, clinical benefit, CNS efficacy, toxicities and pattern of progression were obtained from medical records. Toxicity was reported following the Common Terminology Criteria for Adverse Events (CTCAE 3.0).

Regarding comorbidity, we did not use the Charlson Comorbidity Index due to the strong influence of the presence of metastases (M1) on this scale, but presence of relevant comorbidity used in that scale was registered and graded, and we considered it relevant if patients had one or more comorbidities with grade 2 or higher. In this study the comorbidity that was considered and graded was: diabetes mellitus, hypertension, dyslipidemia, myocardial disease such as myocardial infarction and congestive heart failure, chronic pulmonary disease, liver and renal disease.

\section{Statistical analysis}

The characteristics of patients were described and the Kaplan-Meier method was used to calculate the PFS and OS as the time-to-event for each endpoint from the start date of treatment with eribulin to the occurrence date of the event, progression or death, respectively. An evaluation of the response was performed by the response evaluation criteria in solid tumors (RECIST 1.1.). Objective response rate (ORR) included complete response (CR) and partial response (PR) at the first evaluation (generally performed every 9-12 weeks or if clinically indicated). Clinical benefit rate included CR, PR or stable disease (SD) of at least 6 months' duration.

Statistical differences were estimated using the logrank test. The univariate and multivariate analyses were conducted using the Cox proportional hazard regression model for PFS and OS to assess the prognostic value of patients, tumors and treatment characteristics. A twotailed $p$-value of $<0.05$ was considered significant. In the multivariate analysis, we included the variables that achieved a $p$-value $<0.1$ in the univariate analysis. All analyses were carried out using the SPSS 22.0 statistical software (SPSS Inc., Chicago, IL, USA).

\section{Results}

\section{Patient characteristics}

Ninety-five women with HER2-negative ABC were treated with at least one cycle of eribulin during this period. Baseline patient and tumor characteristics are listed in Table 1. Overall, median age was 57 years (range 33-83), ECOG Performance Status was $\leq 1$ in $88 \%$ of patients and only $12.6 \%$ of patients had relevant comorbidities. Median number of organs involved was 3 (range 1-5). Of those patients with CNS involvement $(n=20)$, seven $(33 \%)$ had been previously treated with whole brain irradiation. In patients pretreated with taxanes, $46 \%$ progressed during the first 3 months and they were considered taxane-refractory, based on previous studies [7]. 
Table 1 Baseline characteristics of the patients included in the study $(n=95)$

\begin{tabular}{|c|c|c|}
\hline Variable & N & $\%$ \\
\hline \multicolumn{3}{|l|}{ Age } \\
\hline$<70$ years old & 79 & $(83 \%)$ \\
\hline$\geq 70$ years old & 16 & $(17 \%)$ \\
\hline \multicolumn{3}{|l|}{ Comorbidities } \\
\hline Hypertension & 13 & $(13,7 \%)$ \\
\hline Dyslipidemia & 9 & $(9.5 \%)$ \\
\hline Diabetes Mellitus & 3 & $(3.2 \%)$ \\
\hline Cardiorespiratory disease & 9 & $(9.5 \%)$ \\
\hline Liver and renal disease & 5 & $(5.3 \%)$ \\
\hline Relevant comorbidity ( $\geq$ grade 2 ) & 12 & $(12.6 \%)$ \\
\hline \multicolumn{3}{|l|}{ BMI } \\
\hline $\mathrm{BMI}<25$ & 43 & $(45 \%)$ \\
\hline BMI 25-30 & 35 & $(37 \%)$ \\
\hline $\mathrm{BMI}>30$ & 17 & $(18 \%)$ \\
\hline \multicolumn{3}{|l|}{ Histology } \\
\hline Infiltrating ductal carcinoma & 84 & $(88 \%)$ \\
\hline Infiltrating lobular carcinoma & 11 & $(12 \%)$ \\
\hline \multicolumn{3}{|l|}{ Tumor subtype } \\
\hline ER and/or PgR positive & 75 & $(79 \%)$ \\
\hline Triple Negative & 16 & $(17 \%)$ \\
\hline HER2-positive & 4 & $(4 \%)$ \\
\hline \multicolumn{3}{|l|}{ Previous chemotherapies } \\
\hline Taxane & 93 & $(98 \%)$ \\
\hline Capecitabine & 93 & $(98 \%)$ \\
\hline Vinorelbine & 33 & $(35 \%)$ \\
\hline \multicolumn{3}{|l|}{ Location of M1 } \\
\hline Bone & 73 & $(77 \%)$ \\
\hline Lymph nodes & 67 & $(71 \%)$ \\
\hline Liver & 62 & $(65 \%)$ \\
\hline Lung & 29 & $(31 \%)$ \\
\hline Pleura & 23 & $(24 \%)$ \\
\hline Central nervous system & 20 & $(21 \%)$ \\
\hline Skin & 19 & $(20 \%)$ \\
\hline \multicolumn{3}{|l|}{ Visceral metastases } \\
\hline Yes & 72 & $(76 \%)$ \\
\hline No & 23 & $(24 \%)$ \\
\hline \multicolumn{3}{|l|}{ Number of organs involved } \\
\hline$\leq 2$ organs & 35 & $(37 \%)$ \\
\hline$>2$ organs & 60 & (63\%) \\
\hline
\end{tabular}

Abbreviations: $B M I$ body mass index, $E R$ estrogen receptor, $P g R$ progesterone receptor

\section{Efficacy of eribulin according to patient and tumor characteristics}

Median number of cycles of eribulin received was 7 (1-55).

Dose interruptions, delays and reductions were 14, 26 and $32 \%$, respectively. ORR was $26.2 \%$ (all of them PR) and $37.5 \%$ of patients had SD, with a clinical benefit observed in $63.7 \%$ of patients. Regarding CNS efficacy, 4 patients (20\%) presented a PR, 5 patients (25\%) achieved SD and 2 patients were not evaluated. Remarkably, out of the nine patients with CNS metastases who progressed during treatment with eribulin, six $(66 \%)$ had meningeal carcinomatosis. In the subgroup of patients without previously known CNS disease, only two patients progressed to meningeal carcinomatosis during treatment with eribulin. Disease control seemed independent to previous CNS local treatment. From the seven patients who had been previously treated with whole brain irradiation, two achieved PR, three SD and two progressed during treatment with eribulin.

A different pattern of ORR was observed in patients based on age ( $<70$ years vs $\geq 70$ years). Clinical benefit was $62 \%$ in the younger group of patients and $51.3 \%$ in the older patients, non-statistically significant $(p=0.299)$, with $25 \%$ vs $31.3 \%$ achieving PR and $37 \%$ vs $20 \%$ achieving SD, respectively.

At a median follow up of 13 months, 16 patients (17\%) were still alive. Median PFS was 4.1 months (95\% CI 3.24.9) and was significantly shorter in patients with more than 2 organs involved (3.3 vs 5.9 months; HR 2; $95 \%$ CI 1.22 $3.26, p=0.01)$; in patients with TNBC compared to those with HR-positive tumors (3.3 vs 4.5 months; HR 4.16; $95 \%$ CI 3.2-4.9, $p=0.041$ ); in patients with visceral involvement (3.8 vs 6.2 months; HR 5.35; 95\% CI 3.2-4.9, $p=0.021$ ); and in patients $<70$ years of age (3.8 vs 6.3 months; HR 1.82; $95 \%$ CI $1.02-3.25, p=0.011)$. Median OS was 11.1 months (95\% CI 9.5-14.67) and, similar to what was observed with PFS, OS was significantly shorter in patients with TNBC compared to those with HR-positive tumors (5.5 vs 12.4 months; HR 3.36; 95\% CI 1.15-4.85, $p=0.049$ ) (Fig. 1a); in patients with more than 2 organs involved (8.4 vs 16.4 months; HR 3.88; 95\% CI 1.95-7.7, $p<0.01$ ) (Fig. 1b); in patients with visceral involvement (9.2 vs 16.4 months; HR 2.33; 95\%CI 1.27-4.2, $p=0.005$ ) (Fig. 1c); and in patients < 70 years of age (9.5 vs 27.8 months; HR 2.202; $95 \%$ CI 1.08-4.4, $p=0.024$ ) (Fig. 1d). Median OS was worse for taxane-refractory patients (7 vs 12.4 months; HR 1.5; $95 \%$ CI 0.406-1.041, $p=0.070$ ) and better for patients who experienced grade 3 or 4 toxicities (13 vs 9.5 months; HR 1.5; 95\% CI 0.916-2.6, $p=0.066$ ), but these differences were not statistically significant. No differences in PFS or OS were observed based on comorbidity or weight.

In the multivariate analysis, only TNBC (HR 2.33; 95\% CI $1.25-448, p=0.011$ ), $>2$ organs involved (HR 2.27; 95\% CI $1.18-4.27, p=0.009$ ) and $<70$ years of age (HR 2.35; 95\% CI 1.07-5.18, $p=0.033)$ were independent prognostic factors for worse OS (Table 2). 


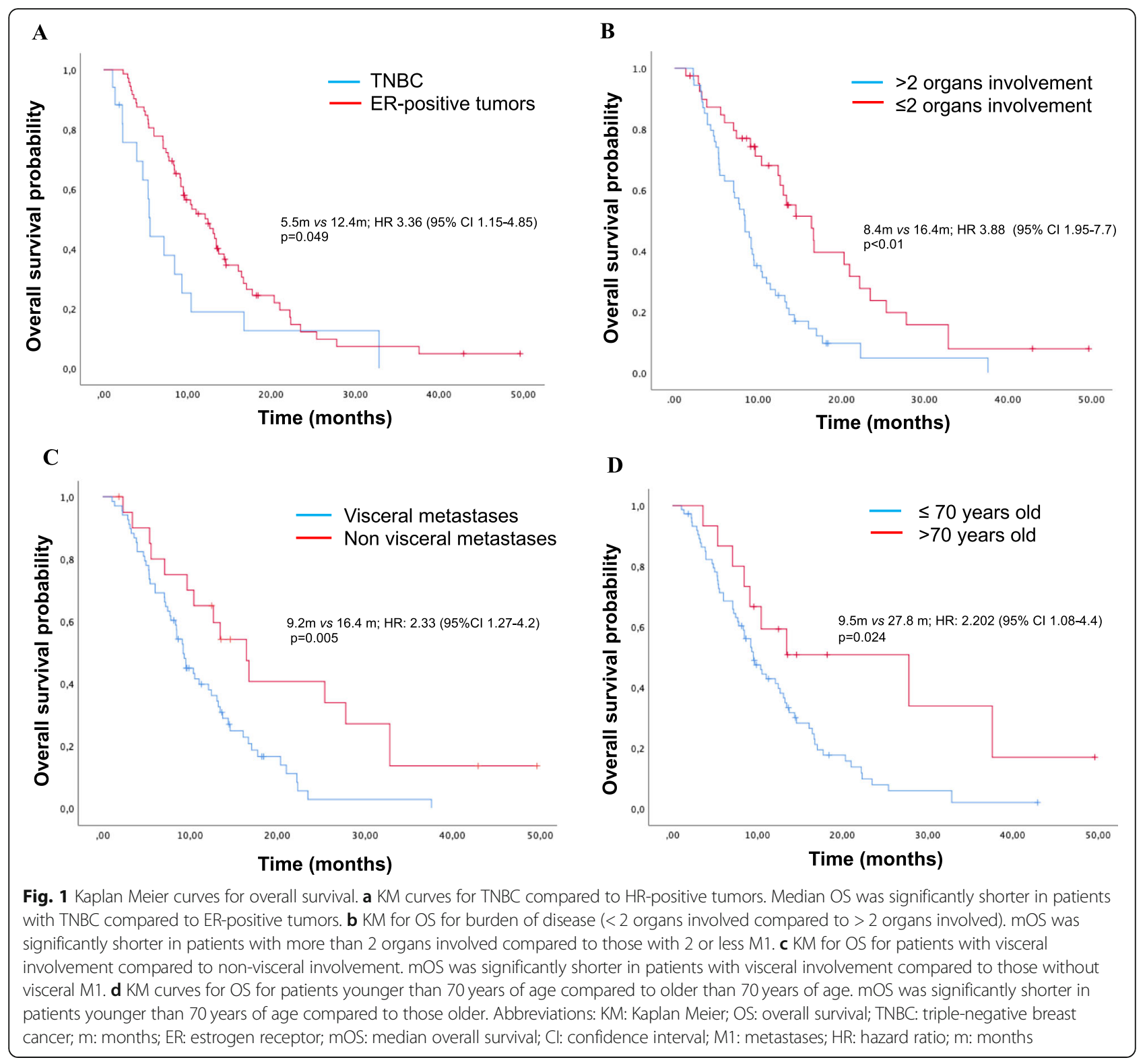

Table 2 Multivariate analysis for OS and basal patient and disease characteristics

\begin{tabular}{lllll}
\hline & $\mathrm{HR}$ & \multicolumn{2}{l}{$95 \% \mathrm{Cl}$ for HR } & $P$ \\
\cline { 3 - 4 } & & Inferior & Superior & \\
\hline Triple negative & 2.334 & 1.215 & 4.481 & 0.011 \\
> 2 organs involvement & 2.272 & 1.19 & 4.274 & 0.013 \\
Age (<70 years old) & 2.354 & 1.070 & 5.180 & 0.033 \\
Visceral metastases & 2.35 & 0.236 & 1.259 & 0.155 \\
Taxane-refractary & 0.977 & 0.566 & 1.688 & 0.934 \\
Grade 3-4 toxicities & 1.723 & 0.966 & 3.072 & 0.065 \\
\hline
\end{tabular}

Abbreviations: OS overall survival, $H R$ hazard ratio, $C l$ confidence interval

\section{Toxicity}

Toxicities are listed in Table 3. Twenty-nine percent of patients suffered grade 3 adverse events (AE) and 10.9\% a grade $4 \mathrm{AE}$ (all neutropenia). The most frequent grade 3 and 4 AEs were asthenia, neurotoxicity and neutropenia and were mainly manageable. All grade 3 and 4 toxicities were independent of a patient's baseline characteristics (age, obesity, tumor subtype, visceral involvement or number of previous chemotherapy regimens). One patient with grade 4 febrile neutropenia with a skin infection died due to septic shock.

\section{Pattern of progression}

Most patients $(n=72 ; 75 \%)$ progressed in pre-existing sites of metastases and only $19(20 \%)$ patients experienced 
Table 3 Most common adverse events following the Common Terminology Criteria for Adverse Events (CTCAE 3.0)

\begin{tabular}{lllllllll}
\hline Grades & Neurotoxicity & Alopecia & Asthenia & Thrombocytopenia & Anaemia & Neutropenia & Oral Mucositis & Hepatotoxicity \\
\hline 1 & $17(18.5 \%)$ & $13(14.1 \%)$ & $36(39.1 \%)$ & $5(5.4 \%)$ & $17(18.5 \%)$ & $4(4.3 \%)$ & $10(10.9 \%)$ & $15(16.3 \%)$ \\
2 & $18(19.6 \%)$ & $11(12 \%)$ & $37(40.2 \%)$ & $2(2.2 \%)$ & $6(6.5 \%)$ & $6(6.5 \%)$ & $3(3.3 \%)$ & $2(2.2 \%)$ \\
3 & $7(7.6 \%)$ & - & $9(9.8 \%)$ & $1(1.1 \%)$ & 0 & $9(9.8 \%)$ & $1(1.1 \%)$ & $2(2.2 \%)$ \\
4 & 0 & - & 0 & 0 & 0 & $10(10.9 \%)^{a}$ & 0 & 0 \\
\hline
\end{tabular}

${ }^{\mathrm{a}}$ Nine out of ten had febrile neutropenia

disease progression in new locations. Four patients out of those 19 (21\%) developed meningeal carcinomatosis. The remaining $5 \%$ of patients had clinical progression without radiological evidence of disease progression. The main cause of treatment release was progression (87\%) followed by toxicity (13\%). Median number of lines of chemotherapy received after eribulin was $1(0-5)$.

\section{Discussion}

In the present analysis of the efficacy of eribulin in an off-trial setting, PFS and OS in patients with heavily pretreated HER2-negative advanced breast cancer were similar to those observed in the phase III EMBRACE trial (4.1 vs 3.7 months and 11.1 vs 13.1 months, respectively) [6-8]. Patient characteristics in our study more closely resemble the patient characteristics in the EMBRACE study population than the 301 study population, as most patients had been previously treated with anthracyclines, taxanes and capecitabine [6]. In contrast, the response rate and clinical benefit in our study were higher than in the EMBRACE trial and more similar to the 301 trial results [7]. There was an increased risk of mortality in patients with TNBC compared to HRpositive disease, given the aggressiveness of this tumor subtype. In the pooled analyses, longer median OS was observed in patients with more than two organs involved and in those with visceral metastases [8]; however, in our study, more benefit and longer OS were seen in patients with lower burden of disease and fewer than two organs involved. The more favourable results obtained in these subgroups of patients may reflect their independent better prognosis $[8,12,20]$.

In previous reports, patient age had not been described as an independent factor for PFS or OS. A pooled analysis of 827 patients treated in either the EMBRACE trial or the preceding phase II studies reported outcomes according to age. A total of $10 \%$ of patients who were included in these studies were aged $\geq 70$ years. No significant differences were observed in ORR, PFS, or OS by age. Toxicity was similar across all age groups, although the incidence of grade 3 and 4 fatigue and peripheral neuropathy was highest in patients aged $\geq 70$ years [14, 21]. Elderly patients with good ECOG-Performance Status treated with eribulin have also shown similar OS, PFS, response rate, clinical benefit and tolerability in smaller studies when compared to younger patients [21, 22]. In our cohort of patients, we observed significant differences in OS according to age, with significantly better OS and PFS in patients $\geq 70$ years of age compared to those younger. Similar ORR but with a distinct pattern regarding PR or SD and tolerability were observed in patients in both age groups.

The role of BMI and comorbidities in the outcomes of patients treated with eribulin is still a matter of debate. In some historical series, patients who are overweight and obese have shown worse outcomes compared to the normal weight group [20, 23, 24]. In an Italian observational multicentric study, there was a significantly better PFS in the lowest category of BMI, but no differences in OS were observed [25]. In our cohort, no differences in OS were found amongst patients with normal weight compared to overweight and obese patients or those with and without comorbidities.

In our study, $21 \%$ of patients had CNS involvement, which is often an exclusion criterion in most clinical trials, unless patients are previously treated with local therapy. Of those patients, 25\% achieved SD and 20\% achieved PR, which supports the efficacy of eribulin in patients with CNS involvement. The efficacy in patients with CNS disease was not related to previous treatment with whole brain radiotherapy. The rationale for potential positive effect of eribulin on brain metastases is not clear. Preclinical evidence suggests that the agent does not cross the blood-brain barrier (BBB) to a significant extent $[15,26]$. Radiation therapy can compromise the $\mathrm{BBB}$, which may help drugs enter into the brain [27]. However, this $\mathrm{BBB}$ drug crossing can be also explained by the altered $\mathrm{BBB}$ due to the presence of brain metastases alone. In the 301 study, a lower proportion of patients in the eribulin arm developed CNS metastases compared to the capecitabine arm (2.4\% vs $4.6 \%$, respectively) [7]. Moreover, in the three patients with known stable brain metastases included in that trial and treated with eribulin, a reduction in the size of brain lesions was also observed. Some case reports have also shown efficacy with eribulin at the CNS level, both in patients previously treated with radiotherapy and not $[28,29]$.

The pattern of disease progression in patients treated with eribulin is distinctive. Most patients in our series progressed in pre-existing M1 sites (75\%). This fact may 
reflect the inhibitory effect of eribulin in the EMT, reducing cancer cell migration and invasiveness; however, we did not find any information about the pattern of progression in patients who received other oncospecific treatments [1-3]. It has been previously reported that patients with $\mathrm{ABC}$ who develop tumour progression with new metastases have worse outcomes compared to those patients whose disease progresses due to growth of pre-existing lesions [11, 30].

Regarding toxicity, most patients in our series demonstrated acceptable tolerability of the eribulin treatment. The most frequent grade 3/4 toxicities were asthenia, neurotoxicity and neutropenia and were manageable. Remarkably, the proportion of grade 3 neutropenia was lower in our study than in pivotal trials ( $9.8 \%$ vs $23.4 \%$ ), as well as grade 4 toxicities with $10.2 \%$ in our study (all of them neutropenia) versus $27.7 \%$ in the pooled analysis [8].

This study has several strengths and limitations. Our study reflects the everyday clinical practice use of eribulin and analyzes multiple variables such as BMI, age $>70$ years and activity in patients with CNS metastases that have not been previously addressed and studied together in patients outside of a clinical trial. The major limitations of this study are the limited number of patients included and its retrospective nature without having a dedicated pre-planned design of patient management and data collection, which can lead to potential biases. It is worth noting that, during the study period, several clinical trials evaluating new targeted drugs in combination with eribulin were ongoing and those patients were not included in this study.

\section{Conclusion}

The efficacy of eribulin in terms of OS and PFS observed in our study is similar to that reported in pivotal clinical trials. However, clinical benefit and ORR were higher, and significantly longer survival was seen in patients with HR-positive tumors, low burden disease and older than 70 years of age. Remarkably, less toxicity was found compared to previous studies and relevant CNS efficacy was observed. Despite the potential biases of this study, its results might be useful in clinical practice due to the limited existing data of eribulin's efficacy and safety focused on age, BMI and CSN.

\footnotetext{
Abbreviations

ABC: Advanced breast cancer; AE: Adverse events; BBB: Blood-brain barrier; BMI: Body mass index; CNS: Central nervous system; CR: Complete response; CTCAE 3.0: Common Terminology Criteria for Adverse Events; ECOG: Eastern Cooperative Oncology Group; EMT: Epithelial-mesenchymal transition; M1: Metastases; OS: Overall survival; PFS: Progression-free survival; PR: Partial response; RECIST 1.1: Response evaluation criteria in solid tumors; SD: Stable disease; TNBC: Triple-negative breast cancer
}

\section{Acknowledgments}

We would like to acknowledge Kaitlyn T. Bifolck, BA, for her editorial support. We thank CERCA Programme/Generalitat de Catalunya for institutional support.

\section{Authors' contributions}

MBS have been the principal contributor of this study, coordinating the data analysis and writing the manuscript with SP. VNP has been focused on the statistical analysis. The rest of the authors (AFO, AS, IM, CF, SV, RC, RV, SR and $M G G)$, have made substantial and equal contribution, by collecting and updating clinical data from patients in this study. They have also agreed to all of the contents and approved the submitted version. SP, as the corresponding author, has ensured that all listed authors have participated in the manuscript and she has been responsible of managing all

communication between the publication and all co-authors, before and after publication. She has ensured that all authors have approved the manuscript and that they will receive the submission and all substantive correspondence with editors.

\section{Funding}

this research received no specific grant from any funding agency in the public, commercial, or not-for-profit sectors.

\section{Availability of data and materials}

The datasets used and/or analyzed during the current study are available from the corresponding author on reasonable request.

\section{Ethics approval and consent to participate}

This study was carried out following relevant guidelines and regulations. This is an observational retrospective study approved by the Ethical Committee from the Institut Català d'Oncologia (ICO). We obtained the written consent from the alive patients to use their data, however most of patients had deceased when the study was conducted, and the Committee considered that it was acceptable to have a verbal consent from them.

\section{Consent for publication}

Not applicable.

\section{Competing interests}

Miguel Gil-Gil has received honoraria from Novartis, Pfizer, Pierre-Fabre and Roche and has advisory role to Daiichi-Sankyo, Novartis and Pfizer. Sonia Pernas has received honoraria for talks and travel grants from Roche, and has served on advisory boards for Polyphor. Catalina Falo has received travel from Pfizer. The rest of the authors have no competing interest to disclosure.

\section{Author details}

'Department of Medical Oncology-Breast Cancer Unit, Insitut Catala d'Oncologia (ICO)-H.U.Bellvitge- IDIBELL, Avinguda Gran Via 199-203, 08908-L'Hospitalet de Llobregat, Barcelona, Spain. ${ }^{2}$ Research Unit, Institut

Català d'Oncologia-(ICO) L'Hospitalet, Barcelona, Spain.

Received: 12 September 2019 Accepted: 25 October 2019

Published online: 21 November 2019

\section{References}

1. Yoshida T, Ozawa Y, Kimura T, Sato Y, Kuznetsov G, Xu S, Uesugi M, Agoulnik S, Taylor N, Funahashi Y, Matsui J. Eribulin mesilate suppresses experimental metastasis of breast cancer cells by reversing phenotype from epithelial-mesenchymal transition (EMT) to mesenchymal-epithelial transition (MET) states. Br J Cancer. 2014;110(6):1497-505. https://doi.org/10. 1038/bjc.2014.80.

2. Bonnomet A, Syne L, Brysse A, Feyereisen E, Thompson EW, Noel A, Foidart $J M$, Birembaut P, Polette M, Gilles C. A dynamic in vivo model of epithelialto-mesenchymal transitions in circulating tumor cells and metastases of breast cancer. Oncogene. 2012;31(33):3741-53. https://doi.org/10.1038/onc. 2011.540.

3. Funahashi $Y$, Okamoto $K$, Adachi $Y$, Semba T, Uesugi M, Ozawa $Y$, Tohyama O, Uehara T, Kimura T, Watanabe H, Asano M, Kawano S, Tizon X, McCracken PJ, Matsui J, Aoshima K, Nomoto K, Oda Y. Eribulin mesylate reduces tumor microenvironment abnormality by vascular remodeling in preclinical human breast cancer models. Cancer Sci. 2014;105(10):1334-42. https://doi.org/10.1111/cas.12488

4. Ueda S, Saeki T, Takeuchi H, Shigekawa T, Yamane T, Kuji I, Osaki A. In vivo imaging of eribulin-induced reoxygenation in advanced breast cancer patients: a comparison to bevacizumab. Br J Cancer. 2016;114(11):1212-8. https://doi.org/10.1038/bjc.2016.122. 
5. Towle MJ, Salvato KA, Wels BF, Aalfs KK, Zheng W, Seletsky BM, Zhu X, Lewis BM, Kishi Y, Yu MJ, Littlefield BA. Eribulin induces irreversible mitotic blockade: implications of cell-based pharmacodynamics for in vivo efficacy under intermittent dosing conditions. Cancer Res. 2011;71(2):496-505. https://doi.org/10.1158/0008-5472.CAN-10-1874.

6. Cortes J, O'Shaughnessy J, Loesch D, Blum JL, Vahdat LT, Petrakova K, Chollet P, Manikas A, Dieras V, Delozier T, Vladimirov V, Cardoso F, Koh $H$, Bougnoux P, Dutcus CE, Seegobin S, Mir D, Meneses N, Wanders J, Twelves $C$, investigators $E$. Eribulin monotherapy versus treatment of physician's choice in patients with metastatic breast cancer (EMBRACE): a phase 3 open-label randomised study. Lancet. 2011;377(9769):914-23. https://doi.org/10.1016/s0140-6736(11)60070-6

7. Kaufman PA, Awada A, Twelves C, Yelle L, Perez EA, Velikova G, Olivo MS, He Y, Dutcus CE, Cortes J. Phase III open-label randomized study of eribulin mesylate versus capecitabine in patients with locally advanced or metastatic breast cancer previously treated with an anthracycline and a taxane. J Clin Oncol. 2015;33(6):594-601. https://doi.org/10.1200/JCO.2013.52.4892.

8. Twelves C, Cortes J, Vahdat L, Olivo M, He Y, Kaufman PA, Awada A. Efficacy of eribulin in women with metastatic breast cancer: a pooled analysis of two phase 3 studies. Breast Cancer Res Treat. 2014;148(3):553-61. https:// doi.org/10.1007/s10549-014-3144-y.

9. Kotake T, Kikawa Y, Takahara S, Tsuyuki S, Yoshi-bayashi H, Suzuki E, Moriguchi $Y$, Yamashiro $H$, Yamagami K, Suwa $H$, Okuno T, Okamura T, Hashimoto T, Kato H, Tsuji A, Toi M. Impact of Eribulin Monotherapy on post-progression survival in patients with HER2negative advanced or metastatic breast Cancer. Int J Cancer Clin Res. 2016;3(4):061.

10. Garrone O, Montemurro F, Saggia C, La Verde N, Vandone AM, Airoldi M, De Conciliis E, Donadio M, Lucio F, Polimeni MA, Oletti MV, Giacobino A, Merlano MC. Eribulin in pretreated metastatic breast cancer patients: results of the TROTTER trial-a multicenter retrospective study of eribulin in real life. Springerplus. 2016:5:59. https://doi.org/10.1186/s40064-016-1700-0.

11. Twelves C, Cortes J, Kaufman PA, Yelle L, Awada A, Binder TA, Olivo M, Song J, O'Shaughnessy JA, Jove M, Perez EA. "New" metastases are associated with a poorer prognosis than growth of pre-existing metastases in patients with metastatic breast cancer treated with chemotherapy. Breast Cancer Res. 2015;17(1):150. https://doi.org/10.1186/s13058-015-0657-1.

12. O'Shaughnessy J, McIntyre K, Schwartzberg L, Wilks S, Puhalla S, Berrak E, Song J, Vahdat L. Impact of prior anthracycline or taxane use on eribulin effectiveness as first-line treatment for metastatic breast cancer: results from two phase 2, multicenter, single-arm studies. Springerplus. 2015;4:532. https://doi.org/10.1186/s40064-015-1322-y.

13. Cashman J, Wright J, Ring A. The treatment of co-morbidities in older patients with metastatic cancer. Support Care Cancer. 2010;18(5):651-5. https://doi.org/10.1007/s00520-010-0813-1.

14. Muss HB. Coming of age: breast cancer in seniors. Oncologist. 2011;16(Suppl 1):79-87. https://doi.org/10.1634/theoncologist.2011-S1-79.

15. Narayan S, Carlson EM, Cheng H, Condon K, Du H, Eckley S, Hu Y, Jiang Y, Kumar V, Lewis BM, Saxton P, Schuck E, Seletsky BM, Tendyke K, Zhang H, Zheng W, Littlefield BA, Towle MJ, Yu MJ. Novel second generation analogs of eribulin. Part III: blood-brain barrier permeability and in vivo activity in a brain tumor model. Bioorg Med Chem Lett. 2011;21(6):1639-43. https://doi. org/10.1016/j.bmcl.2011.01.096.

16. Minisini AM, Moroso S, Gerratana L, Giangreco M, lacono D, Poletto E, Guardascione M, Fontanella C, Fasola G, Puglisi F. Risk factors and survival outcomes in patients with brain metastases from breast cancer. Clin Exp Metastasis. 2013;30(8):951-6. https://doi.org/10.1007/s10585-013-9594-5.

17. Gradishar WJ, Anderson BO, Balassanian R, Blair SL, Burstein HJ, Cyr A, Elias AD, Farrar WB, Forero A, Giordano SH, Goetz MP, Goldstein LJ, Isakoff SJ, Lyons J, Marcom PK, Mayer IA, McCormick B, Moran MS, O'Regan RM, Patel SA, Pierce LJ, Reed EC, Salerno KE, Schwartzberg LS, Sitapati A, Smith KL, Smith ML, Soliman H, Somlo G, Telli M, Ward JH NCCN Clinical Practice Guidelines in Oncology, Breast Cancer, Version 3. 2017. https://www.nccn.org/professionals/physician_gls/pdf/breast.pdf. Accessed 10 Jan 2018.

18. Cardoso F, Harbeck N, Fallowfield L, Kyriakides S, Senkus E, Group EGW. Locally recurrent or metastatic breast cancer: ESMO clinical practice guidelines for diagnosis, treatment and follow-up. Ann Oncol. 2012;23(Suppl 7):vii11-9. https://doi.org/10.1093/annonc/mds232.

19. Cardoso F, Bedard PL, Winer EP, Pagani O, Senkus-Konefka E, Fallowfield LJ, Kyriakides S, Costa A, Cufer T, Albain KS, Force E-MT. International guidelines for management of metastatic breast cancer: combination vs sequential single-agent chemotherapy. J Natl Cancer Inst. 2009;101(17):1174-81. https://doi.org/10.1093/jnci/djp235.

20. Rossi S, Cassano A, Strippoli A, Schinzari G, D'Argento E, Basso M, Barone C. Prognostic and predictive factors of eribulin efficacy in heavily pretreated patients affected by metastatic breast cancer: correlation with tumor biology and previous therapies. Drugs Context. 2017;6:212506. https://doi. org/10.7573/dic.212506.

21. Muss H, Cortes J, Vahdat LT, Cardoso F, Twelves C, Wanders J, Dutcus CE, Yang J, Seegobin S, O'Shaughnessy J. Eribulin monotherapy in patients aged 70 years and older with metastatic breast cancer. Oncologist. 2014; 19(4):318-27. https://doi.org/10.1634/theoncologist.2013-0282.

22. de Nonneville A, Sabatier R, Goncalves A, Extra JM, Tarpin C, Launay S, Tassy $L$, Viens P, Rousseau F. Safety and efficacy of eribulin for "real-world" older patients with metastatic breast cancer. J Geriatr Oncol. 2018;9(3):281-3. https://doi.org/10.1016/j.jgo.2017.11.003.

23. Bao PP, Cai H, Peng P, Gu K, Su Y, Shu XO, Zheng Y. Body mass index and weight change in relation to triple-negative breast cancer survival. Cancer Causes Control. 2016;27(2):229-36. https://doi.org/10.1007/s10552-015-0700-7.

24. Chan DS, Vieira AR, Aune D, Bandera EV, Greenwood DC, McTiernan A, Navarro Rosenblatt D, Thune I, Vieira R, Norat T. Body mass index and survival in women with breast cancer-systematic literature review and metaanalysis of 82 follow-up studies. Ann Oncol. 2014;25(10):1901-14. https://doi. org/10.1093/annonc/mdu042.

25. Barba M, Pizzuti L, Sperduti I, Natoli C, Gamucci T, Sergi D, Di Lauro L, Moscetti L, Izzo F, Rinaldi M, Mentuccia L, Vaccaro A, lezzi L, Grassadonia A, Michelotti A, Landucci E, Perracchio L, Pescarmona E, Di Filippo F, Giordano A, Maugeri-Sacca M, Vici P. Body mass index and treatment outcomes in metastatic breast Cancer patients treated with Eribulin. J Cell Physiol. 2016; 231(5):986-91. https://doi.org/10.1002/jcp.25213.

26. Chang AY, Ying XX. Brain metastases from breast Cancer and response to treatment with Eribulin: a case series. Breast Cancer (Auckl). 2015;9:19-24. https://doi.org/10.4137/BCBCR.S21176.

27. Nieder C, Aandahl G, Dalhaug A. A case of brain metastases from breast cancer treated with whole-brain radiotherapy and eribulin mesylate. Case Rep Oncol Med. 2012;2012:537183. https://doi.org/10.1155/2012/537183.

28. Catania G, Malaguti P, Gasparro S, Cognetti F, Vidiri A, Fabi A. Activity of Eribulin Mesylate in brain metastasis from breast Cancer: a stone in a pond? Oncology. 2018;94(Suppl 1):29-33. https://doi.org/10.1159/000489066.

29. Matsuoka H, Tsurutani J, Tanizaki J, Iwasa T, Komoike Y, Koyama A, Nakagawa K. Regression of brain metastases from breast cancer with eribulin: a case report. BMC Res Notes. 2013;6:541. https://doi.org/10.1186/ 1756-0500-6-541.

30. Kashiwagi S, Tsujio G, Asano Y, Goto W, Takada K, Takahashi K, Morisaki T, Fujita H, Takashima T, Tomita S, Ohsawa M, Hirakawa K, Ohira M. Study on the progression types of cancer in patients with breast cancer undergoing eribulin chemotherapy and tumor microenvironment. J Transl Med. 2018; 16(1):54. https://doi.org/10.1186/s12967-018-1443-5.

\section{Publisher's Note}

Springer Nature remains neutral with regard to jurisdictional claims in published maps and institutional affiliations.

Ready to submit your research? Choose BMC and benefit from:

- fast, convenient online submission

- thorough peer review by experienced researchers in your field

- rapid publication on acceptance

- support for research data, including large and complex data types

- gold Open Access which fosters wider collaboration and increased citations

- maximum visibility for your research: over $100 \mathrm{M}$ website views per year

At BMC, research is always in progress.

Learn more biomedcentral.com/submissions 